\title{
African Journal of Aquatic Science

\section{Acoustic fish biomass assessment in a deep Tunisian reservoir: effects of season and diel rhythm on survey results}

\begin{tabular}{|r|l|}
\hline Journal: & African Journal of Aquatic Science \\
\hline Manuscript ID & AJAS-2016-0017.R4 \\
\hline Manuscript Type: & Research Article \\
\hline Date Submitted by the Author: & 28 -Oct-2016 \\
\hline Keywords: & $\begin{array}{l}\text { North Africa, photoperiod, gas bubbles, fisheries, man-made lake, target } \\
\text { strength }\end{array}$ \\
\hline & $\begin{array}{l}\text { Djemali, Imed; Institut National des Sciences et Technologies de la Mer, } \\
\text { Montfleury-Tunis-Tunisie }\end{array}$ \\
\hline
\end{tabular}

\section{SCHOLARONE" \\ Manuscripts}


Acoustic fish biomass assessment in a deep Tunisian reservoir: effects of season and diel rhythm on survey results

\section{Djemali ${ }^{1}$ and H. Laouar ${ }^{2}$}

1. Institut National des Sciences et Technologies de la Mer, 28 rue du 2 Mars 1934, Centre de Salammbô, 2025, Tunis-Tunisie

2. Centre Technique de l'Aquaculture, 05 rue du Sahel 1009 Montfleury-Tunis-Tunisie.

*Corresponding author, e-mail:Imed.Djemali@instm.rnrt.tn 


\begin{abstract}
To determine the best acoustic sampling period for obtaining fish biomass estimates of a Mediterranean deep reservoir in Tunisia, we carried out day and night surveys in each of four seasons [spring (April), summer (September), autumn (December) and winter (March)]. A Simrad EK60 echosounder, equipped with two $120 \mathrm{kHz}$ split-beam transducers for simultaneous horizontal and vertical beaming, was used to sample the entire water column. Data collected in December were not usable because fish merged with methane gas bubbles. However, fish abundance varied across the other seasons with a peak in acoustic biomass observed during summer nighttime hours that was associated with high water temperatures. Across seasons, the fish occupied the entire water column, and fish schools were rarely observed. The preferential timeframe (i.e. maximum fish detectability and low gas flux) for acoustic sampling was nighttime hours in summer and daytime hours during spring and winter. Our findings highlight the importance of collecting data across seasons and photoperiods when determining an acoustic sampling strategy.
\end{abstract}

Keywords: target strength, fisheries, North Africa, photoperiod, man-made lake, gas bubbles 


\section{Introduction}

Surface water reservoirs have been increasingly developed in Tunisia since the 1980 s to regulate the seasonal stream flows and to provide the necessary water for meeting expanding demands for agriculture and domestic needs (Zouabi et al. 2009). Large scale introduction of freshwater fish species into reservoirs the early 1990s created fisheries to compensate for the lack of marine fish landings and to help reduce rural exodus in areas where unemployment is high; these now must be managed to ensure sustainable output (Djemali et al. 2009). The main species exploited in the reservoirs are carp (Cyprinus carpio), barbel (Barbus callensis), roach (Rutilus rubilio), and rudd (Scardinius erythrophthalmus), as well as species with higher commercial value, such as mullet (Mugil cephalus and Liza ramada) and pikeperch (Sander lucioperca) (Losse et al. 1991). Populations of economically important fishes in the reservoirs remain poorly studied, and there is a critical need for reliable information on the distribution and biomass of these stocks to ensure their effective management (Methot and Wetzel 2013; Cardoso and Haimovici 2015). Hydroacoustic methods provide one potentially important tool for meeting these data requirements.

Acoustic methods have been applied in many inland and marine systems to estimate abundance and size of fish (Simmonds and MacLennan, 2005; Kubecka et al. 2012; Loures and Pompeu 2015; Tupper et al. 2016). Acoustic sampling is an accepted sampling technique and a reliable tool for aquatic ecosystem study particularly in deep lakes (Yule et al. 2009; Rudstam et al. 2013; Rechencq et al. 2014). In shallow waters acoustic techniques are less used due to methodological issues (Balk, 2001). In addition to fish biomass estimates and comparison to fixed gillnets, the advantage of active acoustic sampling is the ability to simultaneously sample across several trophic levels including large carnivorous fish, smaller forage fish, and zooplankton (Trenkel et al. 2011). Relative to capture netting acoustic 
sampling can also include greater coverage of the water column, especially pelagic regions; it is also less size selective and non-invasive (Simmonds and MacLennan 2005). However, there are some limitations of acoustic methods because (1) fish are difficult to detect close to the bottom and (2) they merge with gas bubbles. Night and day acoustic sampling have been performed in order to compensate for low detectability near the bottom given that fish behavior can change on a diel basis (Knudsen et al. 2009; Winfield et al. 2007); however, acoustic software is still unable to discriminate between fish and bubbles (Ostrovsky 2009a; Anderson and Martinez 2015). The amount of methane bubbles in the water column depends on the type of sediment, bottom depth, and the history of sediment degassing; and the outcome of the methane production can be an overestimation of fish biomass estimates (Ostrovsky, 2009b). Thus, to apply acoustic tools for fish biomass estimates, an important first step is considering potential limitations that may be general or system specific.

The goal of this study was to contribute to the development of an acoustic sampling strategy for Tunisian reservoirs and more generally for North African inland waters by evaluating seasonal and diel variation. 


\section{Materials and methods}

\section{Study area}

The Joumine Reservoir, located in the northern region of Tunisia $\left(36^{\circ} 58^{\prime} 48^{\prime \prime}{ }^{\circ} \mathrm{N}\right.$, $9^{\circ} 35^{\prime} 32^{\prime \circ} \mathrm{E}$ ) in the Bizerte province, was filled in 1983 (Figure 1). It provides irrigation waters for 1500 ha of farm land in the Mateur area, which is characterized by a Mediterranean climate (Peel et al. 2007). The reservoir has an area of 660 ha and a maximum depth of 41.1 $\mathrm{m}$ in the winter (Table 1). The fish community in this reservoir consists mainly of the indigenous barbel (Barbus callensis, Cyprinidae), as well as introduced mullets (Mugilidae) and pikeperch (Sander lucioperca, Percidae) (DGPA 2012). Catches from fishers' gillnets were sampled during July 2012 and showed that the fish community consisted of $35 \%$ mullets by weight (two species: Mugil cephalus and Liza ramada), 50\% barbel and 15\% pikeperch. These fish are mainly pelagic (Losse et al. 1991), so they can be detected easily by an echosounder, though distinguishing among the two species is not possible.

Previous hydrobiological sampling of Joumine Reservoir indicated temperature and dissolved oxygen homogeneity in the water column except in summer where a difference of 8 $\mathrm{C}^{\circ}$ was observed between the top and the bottom, with a thermocline at $12 \mathrm{~m}$ of depth in the deepest area of the reservoir (Jenhani A., Institut National Agronomique de Tunisie, unpublished data). Based on these earlier observations, we collected water temperature and dissolved oxygen concentration $0.2 \mathrm{~m}$ under the surface water and $0.2 \mathrm{~m}$ above the bottom near the vantage tower (Figure 1) to detect stratification using a Wissenschaftlich Technische Werkstätten (WTW) depth probe, model oxi 197i (Nova Analytics Company, Weilheim, Germany). Our sampling was limited to one station in the deepest part of the reservoir, because the thermocline and oxycline are detected only in areas $>30 \mathrm{~m}$ of depth (Mouelhi, 2000). 


\section{Acoustic surveys}

Four surveys were carried out, including day and night sampling during four seasons: spring (25 April 2012), summer (06 September 2012), autumn (10 December 2012) and winter (17 March 2013). During these surveys we did not differentiate among the three species.

Because zig-zag acoustic transects give statistically equivalent biomass estimates and size distributions as parallel transects (Guillard and Verges 2007), we decided to use 28 zig-zag transects for safety reasons notably during nighttime sampling. The degree of coverage indices at a constant boat speed of 3 knots, estimated using the formula of Aglen (1983), exceeded the recommended level of 2 for all surveys (Godlewska et al. 2009a) (Table 1). Day surveys and night surveys were completed, on average, in $3 \mathrm{hr}$ and $38 \mathrm{~min}$. To account for fish density gradients that may exist in reservoirs (Kubecka and Wittingerova 1998), the lake was divided into three zones (upstream, middle and downstream) with similar surface areas but different depths (Figure 1).

A portable echosounder (SIMRAD EK60, Kongsberg Maritime AS Horten, Norway) was used. It was equipped with two $120 \mathrm{kHz}$ split-beam transducers connected by a multiplexer to a "General Purpose Transceiver" (GPT). One transducer was circular with a half-power beam width of $7^{\circ}$ and was used for down-looking. The other transducer had an elliptic beam of $4^{\circ} \times 10^{\circ}$ and was used for side-looking. Both transducers were mounted on a stainless steel stand, so that they could be fixed $0.5 \mathrm{~m}$ beneath the surface with the horizontal transducer aimed $2^{\circ}$ below the surface. With a maximum range of $36 \mathrm{~m}$, the bottom of the elliptical beam was at $3 \mathrm{~m}$ of depth. In this way, the 0-3 m layer was sampled by side-looking (Kubecka and Wittingerova 1998) and the deeper layer (> $3 \mathrm{~m}$ ) by down-looking. Night surveys began $1 \mathrm{hr}$ after effective sunset. The echosounder was connected to a portable computer, which provided a real-time display and data storage. A global positioning system (GPS) was used to 
record position during the surveys. The pulse length was fixed at $0.256 \mathrm{~ms}$, and the repetition rate was set at 10 pings per second with transducers pinging alternately. The equipment was field calibrated before each pair of surveys using a 23-mm diameter copper sphere, following the protocol of Foote et al. (1987).

Hydroacoustics data were analyzed using Sonar5-pro software (Balk and Lindem 2006, version 6.0.1), using image analysis that greatly improves fish detection in noisy environments (Balk 2001) such as the surface-water interface. We used the default image analysis settings (Foreground filter $=$ height 5 and width 1 , Background filter $=$ height 55 and width 1 , Offset $+6 \mathrm{~dB}$ ) because they were developed for data with a similar ping rate and range resolution. The SEDs were combined into fish traces using a fish tracking algorithm (Balk and Lindem 2006). To be considered as a fish, the traces needed to have a minimum of 2 echoes, could contain no more than 2 lost echoes, and the maximum depth change between consecutive echoes could not exceed $0.3 \mathrm{~m}$. During data collection, the threshold was set at $70 \mathrm{~dB}$ for the $40 \log \mathrm{R}$ time varied gain (TVG).

During a survey a large number of indeterminate rising traces were observed by downlooking. Therefore, we separated fish from rising targets (bubbles) using the Sonar-5 cross filter tracker (CFT) followed by the track classification system that set up one "fish basket" accepting rising targets assumed to be bubbles and one accepting only non-rising targets assumed to be fish (H. Balk personal communication).

To estimate fish lengths of tracked fish detected by down-looking, we used the all mean pooled fish length-TS relationship of Frouzova et al. (2005) because it was developed for Cyprinidae and Percidae that inhabit Joumine Reservoir.

Down-looking: $\mathrm{TS}_{(\mathrm{dB})}=20.45 \log \left(\operatorname{Lt}_{(\mathrm{mm})}\right)-96.13$, where $\mathrm{dB}$ is in decibel and $\mathrm{Lt}$ is fish total length in millimeters. 
For side-looking, we also used the mean pooled fish length-TS relationship of Frouzova et al. (2005).

Side looking: $\mathrm{TS}_{(\mathrm{dB})}=24.73 \log \left(\mathrm{Lt}_{(\mathrm{mm})}\right)-103.61$, The equations of Frouzova et al. (2005) were developed using the same echo sounder (split beam with a $120 \mathrm{kHz}$ frequency) used in this study.

Each zig and zag was used as the elementary sampling distance unit (ESDU) in order to minimize the effect of area close to the bank. For each transducer and ESDU, we obtained from tracked fish the acoustic size distribution in decibels $(\mathrm{dB})$, the mean TS calculated in the linear domain, and the fish density estimates (fish $\mathrm{ha}^{-1}$ ) calculated by dividing the number of tracked fish by the area of the reservoir surface sampled by the beams. Because biological sampling was impossible, we did not have information on individual fish length and weight. Hence we estimated mean weight of fish detected by down-looking from the predicted mean length using the cube law (Minns 1995) whereby the weight of a fish is proportional to the cube of its length $\left(\mathrm{W}_{(\mathrm{g})}=0.001 \mathrm{~L}^{3}{ }_{(\mathrm{cm})}\right)$. Fish biomass was estimated by multiplying fish density by the average fish weight along each EDSU. The biomass per unit area of the entire water column was the sum of the two (side-looking and down-looking) layers (Kubecka and Wittingerova 1998).

The average density and biomass obtained for each zone of the reservoir corresponded to the weighted average of the ESDU estimates (Sokal and Rohlf 1981; Djemali et al. 2010).

$$
\bar{x}_{p}=\frac{\sum_{i=1}^{i=n}\left(B_{i}^{*} A_{s_{i}}\right)}{\sum_{i=1}^{i=n} A_{S_{i}}}
$$

where $\bar{x} p$ is weighted average biomass (or density), $n$ is the number of ESDUs per zone, $B_{i}$ is the biomass (or density) along ESDU $i$ and $A \mathrm{~s}_{i}$ is the sampled area of transect $i$. 


\section{Statistical analysis}

As the number of detected fish per strata was sometimes low, data were combined across strata to compare TS distributions of fish between day and night sampling. In addition, as data normality could not be assumed, the Mann-Whitney (U) nonparametric test was used to detect differences between the distributions (\%) of TS frequencies (Zar 1999).

Multi-way ANOVAs were used to test the influence of season, photoperiod, strata, and depth (independent variables) on fish density (fish $\mathrm{ha}^{-1}$ ) and biomass $\left(\mathrm{kg} \mathrm{ha}^{-1}\right)$ (dependent variables) with the ESDUs serving as sample units. As it was not possible to discriminate between fish and bubbles within echograms obtained in December, the corresponding data were not considered reliable and thus they were not used in this statistical analysis. Just twoway interaction terms in the final model were included; however, inclusion of three- and fourway interactions did not change the significance of the main factors. In order to compare the biomass between strata and seasons, the multi-way ANOVA was followed by a Tukey HDS post hoc test when significant differences were detected. Dependent data were $\log _{10}$ transformed to stabilize the variance. Statistical tests were performed with "Statistica" Software (version 5.5) with $\alpha$ set at 0.05 .

\section{Results}

\section{Fish behavior and presence of gas bubbles}

Water temperature during spring, autumn, and winter was homogeneous throughout the water column; while in summer, the deep water was colder $\left(<7^{\circ} \mathrm{C}\right)$ than the surface layer. The entire water column was well oxygenated during all sampling periods (Table 1). 
The seasonal echograms showed that fish were largely scattered (Figure 2) during daytime and nighttime, except two small schools that were detected in a single echogram downstream in the summer (Figures 3). Thus, we opted to measure fish biomass through fish counting instead of echo-integration. Fish occupied the entire water column during both photoperiods across seasons, and some individual fish were observed diving as the vessel passed overhead. High proportions $(>80 \%)$ of fish traces were inclined upward in the late autumn acoustic sampling on a diel basis. These targets were likely methane gas bubbles (Anderson and Martinez 2015); and, we therefore opted not to estimate fish densities and biomass for this sampling period. During both night and day surveys in the other seasons, rising targets were uncommon and easily discriminated from fish (Figure 2).

\section{Target strengths, fish density and biomass}

TS distributions gathered by the downward-aimed transducer during the two photoperiods did not differ during spring $(U=99, P=0.58)$, summer $(U=93.5, P=0.85)$ and winter $(U=71$, $\mathrm{P}=0.22$ ). The greatest difference in modal values between night and day was observed in winter with a difference of $-15 \mathrm{~dB}$ (Figure 4). During this season, both day and night TS distributions were bimodal. This could represent two size classes of fish in the reservoir; however, given the size difference in modal lengths it is likely these modes do not represent consecutive year classes.

In layer deeper than $3 \mathrm{~m}$, the mode values of the predicted length frequency were consistently greater during daytime than during the nighttime in winter and spring (Figure 4). Acoustic mean target strengths during summer were similar during nighttime and daytime with a high modal value of $-37 \mathrm{~dB}$ corresponding to a total fish length of $78 \mathrm{~cm}$. In the sidelooking aspect, differences in the TS distributions between night and day collections differed among seasons. A higher proportion of large targets (between -40 and $-31 \mathrm{~dB}$ ) were detected 
in the surface layer during each season, the highest proportion being observed during night surveys of winter.

Average fish density differed between day and night when estimation was possible (i.e. spring, summer, and winter, Table 2). In spring, with vertical beaming, average values showed clear trends according to area (Figure 5). During the summer, daytime values measured by vertical beaming were always lower than nighttime regardless of strata; however, during winter it was the opposite. The number of fish per hectare measured in the upper layer was lower than in the deep layer (Table 2) during spring, summer and winter, evidence that the majority of the fish occupied the deep layer. In addition, fish density differed among strata (Table 2) with a gradient from downstream to upstream at water column depths $>3 \mathrm{~m}$ during daytime (Figure 5). Inversely, during nighttime, no clear trends could be detected among fish densities between strata.

Biomass also differed between night- and day-sampling (Table 2). During spring and winter, daytime values were higher than nighttime (Figure 5). In spring, this result corresponded with higher densities in downstream and middle areas. In summer, higher biomass was measured at nighttime than daytime and was correlated with higher densities. During summer and winter biomass was lower in the upper $3 \mathrm{~m}$ suggesting that most of the fish biomass was found at water column depths $>3 \mathrm{~m}$. In spring it was the opposite with fish biomass greater near the surface. There were also significant interactive effects between layers and seasons (Table 2). Overall results indicate that biomass distributions in the water column are dependent on season.

Biomass estimates differed among the three seasons for which acoustic estimation was possible (Table 2). Biomass increased from spring to summer and decreased from summer to winter (Tukey post-hoc test, $\mathrm{P}<0.01$ ). Average acoustic biomass peaked in summer nighttime 
with $140 \pm 37 \mathrm{~kg} \mathrm{ha}^{-1}$ related to a high proportion of large fish in the deepest area of the reservoir (Figure 6) and corresponded to a biomass of 19 metric tons (MT).

\section{Discussion}

This study quantified seasonal and diel acoustic data in order to estimate the biomass of fish in a deep Tunisian reservoir. We highlighted some technical limitations using acoustic methods because of high methane gas ebullition on a diel basis during autumn, which prevented fish discrimination from bubbles and therefore biomass estimation. Our findings demonstrate, for this system, that quantifying variation across seasons and between photoperiods is important in improving the rigor of acoustic sampling; that gas bubble emissions can affect the accuracy of estimates during the colder season; and that the preferential timeframe for acoustic sampling is nighttime (i.e. higher detectability than daytime) in summer; while during spring and winter it is daytime, highlighting changes in the

\section{diel pattern of fish behavior among seasons.}

Results of this study showed higher biomass estimates in the summer, which may reflect a concentration of large fish at nighttime in the deepest area of the reservoir. Overall, reservoir biomass was obtained by weighting strata biomass, so more importance was given to the deepest area rich in fish. Fishers avoid this area because its access is forbidden by authorities, in particular near the vantage tower. Based on our summer nighttime survey, biomass in Joumine Reservoir was estimated to be 19 MT, but annual exploitation of the fishery does not exceed a yield of 4-6 metric tons (DGPA, 2012). Despite the problem of gas bubbles in December that precluded good biomass estimates, biomass-based acoustic survey methods showed the potential to assess between-season changes in fish abundance in this system. It will be useful in long-term monitoring of productivity and therefore management in deep 
Tunisian's reservoirs similar to what Pollom and Rose (2015) and Loures and Pompeu, (2015) showed for a boreal lake and a Brazilian reservoir, respectively.

\section{Mobile acoustic sampling}

The present study provided evidence of fish diving towards the reservoir bottom when disturbed by the passing boat. Avoidance is a phenomenon of fish behavior that can introduce uncertainties in mobile acoustic sampling results (De Robertis and Handegard 2013). Depth from the boat (Guillard et al. 2010) and differences in the sizes of fish present (Godlewska et al. 2009b) can also affect how fish in lakes respond to an acoustic survey vessel. The ideal situation is that fish are undisturbed. The reaction of fish to the passage of a boat can result in lateral or vertical movements. Lateral avoidance may cause fewer fish to be ensonified, and may or may not effect TS estimation. Diving responses may alter both the measured depth distribution, and the angle of a fish's body relative to the acoustic beam, potentially impacting both TS measurements and coincident integrated backscatter (Wheeland and Rose, 2015). We were able to minimize our underestimation in the surface blind zone by incorporating sidelooking, but we still lack standard approaches to quantify or limit bias from boat avoidance. Joumine is a deep reservoir, but maximum depth does not exceed $40 \mathrm{~m}$ downstream, so avoidance may be a significant issue (Drastik and Kubescka 2005) especially upstream. Mullet and barbel are benthophages (Glamuzina et al. 2007; Pegg and Britton, 2011) resulting in a higher individual tilt, and therefore a lower TS when feeding. Differences in TS distribution in winter with higher modal values daytime with vertical beaming, suggest that fish in Joumine mainly feed at night. The risk of mortality during the feeding process can influence behavior of prey fish on a diel basis as they try to balance their own energy needs while reducing their vulnerability to predators (Schneider et al. 2014). 


\section{Local freshwater fishing}

In Tunisia, freshwater fishing is a secondary activity for populations. In fact, these fishers are mainly farmers who livelihoods are based on sheep or chicken-farming; and fishing activities allow them to improve their revenue in poor areas (Hadj salah 2002). Low fish exploitation is mainly due to the use of unsuitable artisanal fishing gears. Indeed, local fishers generally use gillnets with a height $<7 \mathrm{~m}$, which are fixed near the banks. In deep waters, these fishing gears are ineffective. Given that the largest mullet's catches occur in the spawning months (i.e. September) of the species (Mendonça and Bonfante 2011), it would be interesting to increase fishing effort during this time because the fish will be closer to the bank. In its repartition area, Mugilidae are high in abundance and accessibility meaning that they are targeted by commercial and artisanal seiners and gillnetters throughout their range, and by recreational fishers in developed countries (Broadhurst et al. 2011). Because outboard motors are forbidden in Tunisian's reservoirs, and the use of seines is excluded, deep-water angling in the context of recreational activity might be an important way to utilize the fishery in the deeper area of the lake.

Thermal and trophic conditions from spring to late summer in Tunisian reservoirs are considered favorable for active feeding and growth of fish (Mhetli et al. 2011). Therefore, new production both from successful reproduction (Cejko et al. 2014) and significant growth, likely leads to an increase in the standing biomass of fish. The local fishers unanimously say that catchability of fish increases in September, and this has been confirmed by yield statistics (DGPA 2012). Fishers have attributed this phenomenon to increased water turbidity with the first rains of August-September making their nets less visible to fish. In this study we showed increasing fish biomass from April to September, which suggests that the reputed explanation for higher catch rates is, in fact, probably linked to a response of fish growth during warm months. Indeed, during the spring bloom the turbidity increases significantly (Jenhani A., 
Institut National Agronomique de Tunisie, unpublished data), but catches are unaffected (DGPA 2012).

We conclude that the preferential period for acoustic sampling in the Joumine Reservoir is nighttime hours in summer and daytime hours in spring and winter. It was impossible to estimate fish acoustic biomass during the colder season of autumn because of the disturbing biogeochemical phenomenon of gas bubble emissions. This study showed that fish distribution within the water column may stay unchanged across seasons but fish behavior can change on a diel basis influencing biomass estimation. Moreover, our surveys showed that fish biomass can changed significantly over seasons and reach a maximum in summer nighttime. Considering total fish standing biomass in present study (19 MT) versus official yields (4-6 MT), further acoustic surveys within season will be necessary in order to confirm that the fish stocks are underexploited.

Acknowledgements The study was financed by the Tunisian Ministry for Higher Education and Scientific Research, and was carried out as part of the research project "MIHEC". We express our gratitude to the people in charge of regional fishing in the district of Bizerte for their assistance. We thank Dr. H. Balk (University of Oslo, Norway), the developer of Sonar5 software for his kind help. We also thank Dr. J. Guillard (INRA Thonon les Bains, France) and D.L. Yule (US Geological Survey) for their scientific support. We also thank the two anonymous referees for their helpful reviews. 


\section{Figures}

Figure 1: Map of the Joumine Reservoir and its location within Tunisia and Africa, showing the three geographic strata $(\mathrm{U}=$ upstream; $\mathrm{M}=$ middle; and $\mathrm{D}=$ downstream $)$ and the numbers of zig-zag transects (between brackets). $Z_{\max }$ represent the maximum depth per strata.

Figure 2: Example of a downward-looking echogram (40 $\log \mathrm{R}$ with a $-70 \mathrm{~dB}$ as threshold) showing how fish were distributed in the water column of the Joumine Reservoir during day and night surveys over four seasons: spring (S), summer (SU), autumn (A) and winter (W)

Figure 3: Downward-looking echogram (20 log R with -70 dB as threshold) showing schools of fish, which were only observed, fish in the water column, and fish diving during the summer daytime period.

Figure 4: Target strength (TS in decibel, dB) frequency distributions of target sampled in Joumine Reservoir by down-looking (D) and side-looking (S) sampling in three seasons. The $\mathrm{n}$ and n' represent the number of tracked targets detected during day and night surveys, respectively. Dotted lines and black lines represent day and night data, respectively. Predicted total fish length $\left(\mathrm{L}_{\mathrm{t}}\right)$ was obtained with the formula of Frouzova et al. (2005) in vertical and horizontal beaming.

Figure 5: Mean fish biomass and density measured by down-looking (D) and side-looking (S) sampling in three zones $(\mathrm{u}=$ upstream; $\mathrm{m}=$ middle; and $\mathrm{d}=$ downstream $)$ of the Joumine Reservoir sampled in four seasons. The white bars correspond to day surveys and black bars correspond to night surveys. Error bars show standard deviations. Seasons are shown in each panel, abbreviated as follows: spring $=\mathrm{S}$, summer $=\mathrm{SU}$ and winter $=\mathrm{W}$. 
Figure 6: Fish biomass of the entire water column for each $250 \mathrm{~m}$ ESDU of Joumine Reservoir during summer nighttime survey.

1

2

3

4

5

6

7

8

9

10

11

12

13

14

15

16

17

18

19

20

21

22

23

24

25

26

27

28

29

30

31

32

33

34

35

36

37

38

39

40

41

42

43

44

45

46

47

48

49

50

51

52

53

54

55

56

57

58

59

60 


\author{
List of tables
}

Table 1: Hydraulic characteristics of the Joumine Reservoir when surveyed, and the degree of coverage of the four seasonal acoustic surveys. Water temperature and dissolved oxygen concentration were measured downstream near the vantage tower (see Figure 1 for location).

Table 2: Multi-way analysis of variance (ANOVA) of fish density (fish ha ${ }^{-1}$ ) and biomass (kg $\left.\mathrm{ha}^{-1}\right)$. The independent variables included photoperiod, layer, season and strata. 


\section{References}

Aglen A. 1983. Random errors of acoustic fish abundance estimates in relation to the survey grid density applied. FAO Fisheries Report 300: 293-298.

Anderson MA, Martinez D. 2015. Methane gas in lake bottom sediments quantified using acoustic backscatter strength. Journal of Soil Science 15: 1246-1255.

Balk H. 2001. Development of hydroacoustic methods for fish detection in shallow water. $\mathrm{PhD}$ thesis, University of Oslo, Norway.

Balk H, Lindem T. 2006. Sonar4, Sonar5, Sonar6 post processing systems, operator manual version (5.9.6) $411 \mathrm{pp}$.

Broadhurst MK, Butcher PA, Cullis BR. 2011. Post-release mortality of angled sand mullet (Myxus elongatus: Mugilidae). Fisheries Research 107: 272-275.

Cardoso LG, Haimovici M. 2015. Long-term changes in the age structure, mortality and biomass of the king weakfish Macrodon atricauda (Günther, 1880) in southern Brazil: Is it resilient enough to avoid collapse? Fisheries Research 167: 174-179.

Cejko BI, Krejszeff S, Judycka S, Sarosiek B, Dietreach M, Kucharczyk D, Kowalski RK. 2014. Sperm quality and selected biochemical markers of seminal plasma at the beginning of the reproductive period of common carp, Cyprinus carpio L. Aquaculture International 22: 111-122.

De Robertis A, Handegard NO. 2013. Fish avoidance of research vessels and the efficacy of noise-reduced vessels: a review. ICES Journal of Marine Science 70: 34-45.

DGPA. 2012. Direction Générale de la Pêche et de l'Aquaculture, Agriculture Ministry. Statistiques de pêche de la Direction Générale de la Pêche et de l’Aquaculture. 
Djemali I, Laouar H, Toujani R. 2010. Distribution patterns of fish biomass in three Tunisian man-made lakes by acoustic surveys. Journal of Applied Ichthyology 26: 390-396.

Djemali I, Toujani R, Guillard J. 2009. Hydroacoustic fish biomass assessment in man-made lakes in Tunisia, horizontal beaming importance and diel effect. Aquatic Ecology 43: $1121-1131$.

Drastik V, Kubecka J. 2005. Fish avoidance of acoustic survey boat in shallow waters. Fisheries Research 72: 219-228.

Foote KG, Knutsen H, Vestnes G, MacLennan DN, Simmonds EJ. 1987. Calibration of acoustic instruments for fish density estimation. ICES Cooperative Research Report. 144 pp.

Frouzova J, Kubecka J, Balk H, Frouz J. 2005. Target strength of some European fish species and its dependence on fish body parameters. Fisheries Research 75: 86-96.

Glamuzina B, Dulčić J, Conides A, Bartulović V, Matić-Skoko S, Papaconstantinou C. 2007. Some biological parameters of the thin-lipped mullet, Liza ramada (Pisces, Mugilidae) in the Neretva River delta (Eastern Adriatic, Croatian coast). Vie et Millieu 57: 131-136.

Godlewska M, Długoszewski B, Doroszczyk L, Joźwik A. 2009a. The relationship between sampling intensity and sampling error - empirical results from acoustic surveys in Polish vendacelakes. Fisheries Research Special Issue 96:17-22.

Godlewska M, Dugoszewki B, Doroszczyk L. 2009b. Day/night effects of passing boat on fish distribution in the shallow Malta reservoir. Hydroacoustics 12: 61-68.

Guillard J, Balay P, Colon M, Brehmer P. 2010. Survey boat effect on YOY fish schools in a pre-alpine lake: evidence from multibeam sonar and split-beam echosounder data. Ecology of Freshwater Fish 19: 373-380. 
Guillard J, Vergès C. 2007. The repeatability of biomass estimates and fish size distributions by hydroacoustic surveys using different sampling strategies and statistical methods. International Review of Hydrobiology 92: 605-617.

Hadj Salah H. 2002. Etude socio économique et de rentabilité de l'activité de pêche dans les eaux douces de Tunisie. PhD thesis, Université de Rennes, France.

Knudsen FR, Hawkins AD, McAllen R, Sand O. 2009. Diel interactions between sprat and mackerel in a marine lough and their effects upon acoustic measurements of fish abundance. Fisheries Research 100: 140-147.

Kubecka J, Godø OR, Hickley P, Prchalova M, Riha M, Rudstam L, Welcomme R. 2012. Fish sampling with active methods. Fisheries Research 12: 1-3.

Kubecka J, Wittingerova M. 1998. Horizontal beaming as a crucial component of acoustic fish biomass assessment in freshwater lakes. Fisheries Research 35: 99-106.

Losse GF, Nau W, Winter M. 1991. Le développement de la pêche en eau douce dans le nord de la Tunisie, projet de coopération technique Tuniso-Allemande : Utilisation de barrages pour la pisciculture, GTZ-CGP.

Loures RC, Pompeu PS. 2015. Seasonal and diel changes in fish distribution in a tropical hydropower plant tailrace: evidence from hydroacoustic and gillnet sampling. Fisheries Management and Ecology 22: 185-196.

Mendonça JT, Bonfante TM. 2011. Avaliação e gestão da pesca do parati mugil curema (Valencienne, 1836) (Mugilidade) no litoral sul do estado de São Paulo [Assessment and management of white mullet Mugil curema (Valencienne, 1836) (Mugilidae) fisheries of the south coast of São Paulo state, Brazil] Brazilian Journal of Biology 71: 663-672.

Methot RD, Wetzel CR. 2013. A Biological and statistical framework for fish biomass assessment and fishery management. Fisheries Research 142: 86-99. 
Mhetli M, Ben Khemis I, Hamza N, Turki B, Turki O. 2011. Allometric growth and reproductive biology traits of pikeperch Sander lucioperca at the southern edge of its range. Journal of Fish Biology 78: 567-579.

Minns CK. 1995. Allometry of home range size in lake and rivers fishes. Canadian Journal of Fisheries and Aquatic Sciences 52: 1499-1508.

Mouelhi S. 2000. Etude écologique de la retenue de Sidi Salem: Aspects physico-chimique des eaux et dynamique des peuplements zooplanctoniques. $\mathrm{PhD}$ thesis, Université de Tunis, Tunisie.

Ostrovsky I. 2009a. Hydroacoustic assessment of fish abundance in the presence of gas bubbles. Limnology and Oceanography: Methods: 309-318.

Ostrovsky I. 2009b. The acoustic quantification of fish in the presence of methane bubbles in the stratified Lake Kinneret, Israel. ICES Journal of Marine Science 66: 1043-1047.

Peel MC, Finlayson BL, McMahon TA. 2007. Updated world map of the Köppen-Geiger climate classification. Hydrology and Earth System Sciences 11: 1633-1644.

Pegg JJ, Britton JR. 2011. Effects of inter- and intra-specific competition on the growth rates of juvenile European barbell Barbus barbus used in the stock enhancement of UK fisheries. Fisheries Research 112: 8-12.

Pollom RA, Rose GA. 2015. Size-based hydroacoustic measures of within-season fish abundance in a boreal freshwater ecosystem. PLOS ONE 10: e0124799.

Rechencq M, Vigliano PH, Macchi PJ, Gustavo Enrique Lippolt GE. 2014. Fish distribution patterns and habitat availability in lakes Moreno Esteand Moreno Oeste, Patagonia, Argentina. Limnologica 49: 73-83.

Rudstam LG, Jech JM, Parker-Stetter SL, Horne JK, Sullivan PJ, Mason DM. 2013. Fisheries Acoustics. In: Zale AV, Parrish DL, Sutton TM (ed.), Fisheries techniques, 3 rd Bethesda (MD). American Fisheries Society. 
Schneider J, Worischka S, Hellmann C, Benndorf J, Winkelmann C. 2014. Flexibility in feeding periodicity of a grazing mayfly in response to different concentrations of benthivorous fish. Limnologica 45: 24-32.

Simmonds J, MacLennan DN. 2005. Fisheries acoustics: theory and practice (ed.). Blackwell Publishing. Oxford (UK).

Sokal RR, Rohlf FJ. 1981. Biometry, 2nd ed., WH Freeman, San Francisco.

Trenkel VM, Ressler PH, Jech M, Giannoulaki M, Taylor C. 2011. Underwater acoustics for ecosystem based management. State of the science and proposals for ecosystem indicators. Marine Ecology Progress Series 442: 285-301.

Tupper de Kerckhove D, Shutera BJ, Milne S. 2016. Acoustically derived fish size-spectra within a lake and the statistical power to detect environmental change. Accepted, Canadian Journal of Fisheries and Aquatic Sciences.

Wheeland LJ, Rose GA. 2015. Quantifying fish avoidance of small acoustic survey vessels in boreal lakes and reservoirs. Ecology of Freshwater Fish 24: 67-76.

Winfield IJ, Fletcher JM, James JB. 2007. Seasonal variability on the abundance of Arctic charr (Salvelinus alpinus (L.)) recorded using hydroacoustics in Windermere, UK and its implications for survey design. Ecology of Freshwater Fish 16: 64-69.

Yule DL, Stockwell JD, Schreiner DR, Evrard LM, Balge M, and Hrabik TR. 2009. Can pelagic forage fish and spawning cisco (Coregonus artedi) biomass in the western arm of Lake Superior be assessed with a single summer survey? Fisheries Research 96: 39-50.

Zar JH. 1999. Biostatistical analysis, 4th edn. Prentice Hall, Englewood Cliffs.

Zouabi-Aloui B, Gueddari M. 2009. Long-Term water quality monitoring of the Sejnane Reservoir in North East Tunisia, Bulletin of Engineering Geology and the Environment 68: $307-316$. 
Figure 1: Map of the Joumine Reservoir and its location within Tunisia and Africa, showing the three geographic strata ( $U$ = upstream; $M=$ middle; and $D=$ downstream) and the numbers of zig-zag transects (between brackets). Zmax represent the maximum depth per strata.

$222 \times 125 \mathrm{~mm}(150 \times 150 \mathrm{DPI})$ 
Figure 2: Example of a downward-looking echogram (40 log $\mathrm{R}$ with a $-70 \mathrm{~dB}$ as threshold) showing how fish were distributed in the water column of the Joumine Reservoir during day and night surveys over four seasons: spring $(\mathrm{S})$, summer $(\mathrm{SU})$, autumn $(\mathrm{A})$ and winter $(\mathrm{W})$

$$
318 \times 220 \mathrm{~mm}(150 \times 150 \mathrm{DPI})
$$


Figure 3: Downward-looking echogram (20 log R with $-70 \mathrm{~dB}$ as threshold) showing schools of fish, which were only observed, fish in the water column, and fish diving during the summer daytime period.

$209 \times 84 \mathrm{~mm}(150 \times 150$ DPI $)$ 
Figure 4: Target strength (TS in decibel, dB) frequency distributions of target sampled in Joumine Reservoir by down-looking (D) and side-looking (S) sampling in three seasons. The $\mathrm{n}$ and $\mathrm{n}^{\prime}$ represent the number of tracked targets detected during day and night surveys, respectively. Dotted lines and black lines represent day and night data, respectively. Predicted total fish length (Lt) was obtained with the formula of Frouzova et al. (2005) in vertical and horizontal beaming.

$303 \times 266 \mathrm{~mm}(150 \times 150 \mathrm{DPI})$ 

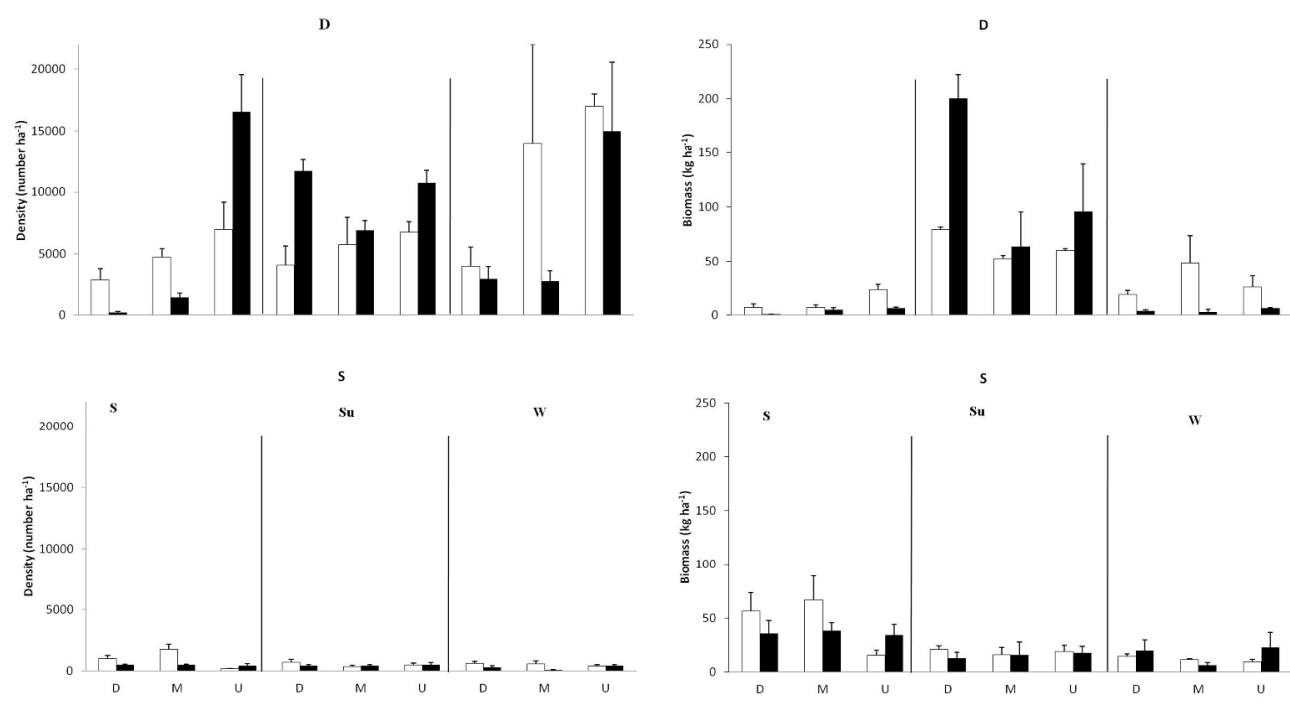

Figure 5: Mean fish biomass and density measured by down-looking (D) and side-looking (S) sampling in three zones ( $u=$ upstream; $m=$ middle; and $d=$ downstream) of the Joumine Reservoir sampled in four seasons. The white bars correspond to day surveys and black bars correspond to night surveys. Error bars show standard deviations. Seasons are shown in each panel, abbreviated as follows: spring $=\mathrm{S}$, summer $=$ SU and winter $=\mathrm{W}$.

$410 \times 220 \mathrm{~mm}(150 \times 150 \mathrm{DPI})$ 


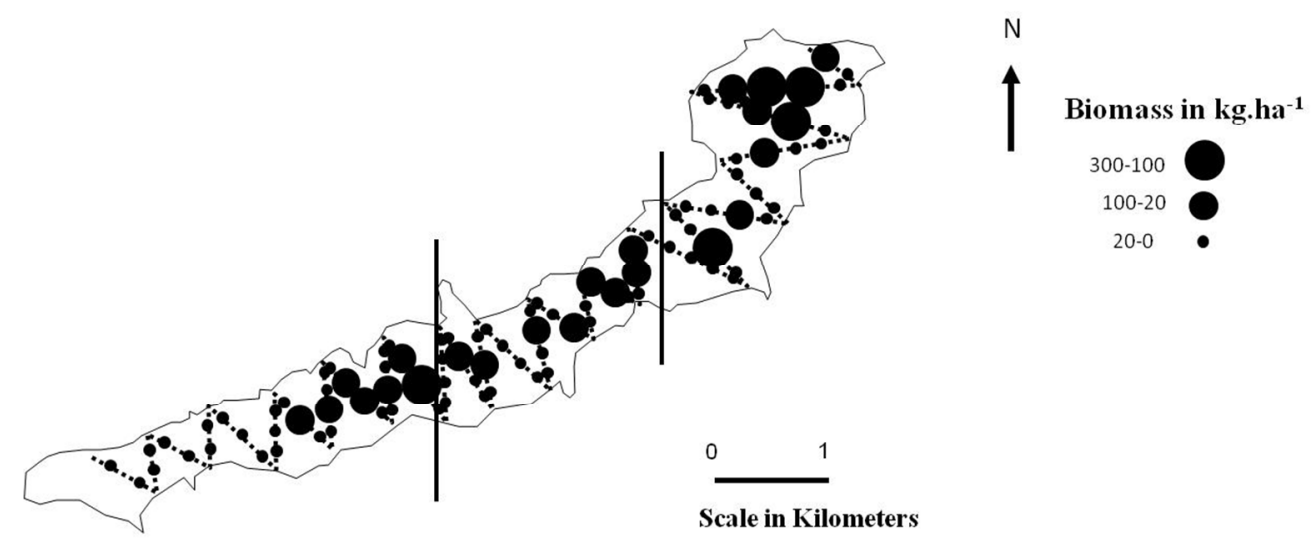

Figure 6: Fish biomass of the entire water column for each $250 \mathrm{~m}$ ESDU of Joumine Reservoir during summer nighttime survey.

$208 \times 89 \mathrm{~mm}(150 \times 150 \mathrm{DPI})$ 


\begin{tabular}{|c|c|c|c|c|c|c|c|}
\hline Season & $\begin{array}{l}\text { Sampling } \\
\text { period }\end{array}$ & $\begin{array}{c}\text { million } \\
\mathbf{m}^{3}\end{array}$ & Area & $\begin{array}{c}\text { Maximu } \\
\text { m } \\
\text { depth } \\
\text { m }\end{array}$ & $\begin{array}{c}\text { Vertical } \\
\text { average } \\
\text { temperature } \\
\text { surface/bottom } \\
{ }^{\circ} \mathrm{C}\end{array}$ & $\begin{array}{c}\text { Vertical } \\
\text { average oxygen } \\
\text { concentration } \\
\text { surface/bottom } \\
\text { mg L }^{-1}\end{array}$ & $\begin{array}{c}\text { Coverage } \\
\text { degree } \\
\text { day/night }\end{array}$ \\
\hline Spring & $25 / 04 / 2012$ & 130.0 & 626 & 38.5 & $16.1 / 15.8$ & 7.3/7.2 & $6.1 / 6.8$ \\
\hline Summer & $06 / 09 / 2012$ & 130.0 & 622 & 36.3 & $25.8 / 17.6$ & $6.4 / 6.1$ & $6.3 / 6.2$ \\
\hline Autumn & $10 / 12 / 2012$ & 163.0 & 659 & 39.8 & $13.0 / 12.8$ & 8.9/8.4 & $6.3 / 6.1$ \\
\hline Winter & $19 / 03 / 2013$ & 188.0 & 692 & 41.1 & $14.8 / 14.7$ & 8.6/8.0 & $6.8 / 6.0$ \\
\hline
\end{tabular}




\begin{tabular}{|c|c|c|c|c|}
\hline$\overline{\text { Effect }}$ & Sum of square & $\overline{d f}$ & $\bar{F}$ & $\bar{P}$ \\
\hline \multicolumn{5}{|l|}{ Density } \\
\hline Photoperiod (P) & 4.11 & 1 & 554.61 & $<0.0001$ \\
\hline Layer (L) & 1.20 & 1 & 17.90 & $<0.0001$ \\
\hline Season (S) & 0.60 & 2 & 53.15 & $<0.0001$ \\
\hline Strata (ST) & 0.12 & 2 & 355.42 & $<0.001$ \\
\hline$P \times L$ & 0.45 & 1 & 7.60 & $<0.001$ \\
\hline$P \times S$ & 3.22 & 2 & 15.91 & $<0.01$ \\
\hline $\mathrm{L} \times \mathrm{S}$ & 1.71 & 2 & 5.64 & $<0.01$ \\
\hline $\mathrm{P} \times \mathrm{ST}$ & 1.66 & 2 & 5.85 & $<0.001$ \\
\hline Lx ST & 2.35 & 2 & 13.20 & $<0.01$ \\
\hline $\mathrm{S} \times \mathrm{ST}$ & 3.50 & 2 & 7.82 & $<0.01$ \\
\hline \multicolumn{5}{|l|}{ Biomass } \\
\hline Photoperiod (P) & 21.40 & 1 & 334.82 & $<0.0001$ \\
\hline Layer (L) & 3.21 & 1 & 155.30 & $<0.0001$ \\
\hline Season (S) & 9.30 & 2 & 277.72 & $<0.0001$ \\
\hline Strata (ST) & 3.12 & 2 & 56.45 & $<0.001$ \\
\hline $\mathrm{P} \times \mathrm{L}$ & 8.75 & 1 & 75.41 & $<0.01$ \\
\hline$P \times S$ & 1.25 & 2 & 14.69 & 0.03 \\
\hline $\mathrm{L} \times \mathrm{S}$ & 2.62 & 2 & 2.48 & $<0.01$ \\
\hline $\mathrm{P} \times \mathrm{ST}$ & 1.54 & 2 & 15.70 & $<0.001$ \\
\hline Lx ST & 3.25 & 2 & 32.65 & $<0.01$ \\
\hline $\mathrm{S} \times \mathrm{ST}$ & 4.56 & 2 & 28.23 & $<0.01$ \\
\hline
\end{tabular}

$d f$, degree of freedom; F, computed statistic for test of significance and $P$, probability 